\title{
A MULTI-SCREENING APPROACH FOR MARINE-DERIVED FUNGAL METABOLITES AND THE ISOLATION OF CYCLODEPSIPEPTIDES FROM Beauveria felina
}

\author{
Aline Maria de Vita-Marques, Simone P. Lira and Roberto G. S. Berlinck* \\ Instituto de Química de São Carlos, Universidade de São Paulo, CP 780, 13560-970 São Carlos - SP, Brazil \\ Mirna H. R. Seleghim \\ Departamento de Ecologia e Biologia Evolutiva, Universidade Federal de São Carlos, São Carlos - SP, Brazil \\ Sandra R. P. Sponchiado \\ Departamento de Bioquímica e Tecnologia Química, Universidade Estadual Paulista, Araraquara - SP, Brazil \\ Sâmia M. Tauk-Tornisielo \\ Centro de Estudos Ambientais, Universidade Estadual Paulista, Av. 24-A, 1515, 13506-900 Rio Claro - SP, Brazil \\ Margarida Barata \\ Departamento de Biologia Vegetal (Microbiologia), Centro de Biologia Ambiental, Faculdade de Ciências de Lisboa, Lisboa, Portugal \\ Claudia Pessoa, Manoel O. de Moraes and Bruno Coêlho Cavalcanti \\ Departamento de Fisiologia e Farmacologia, Universidade Federal do Ceará, Fortaleza - CE, Brazil \\ Gislene G. F. Nascimento \\ Faculdade de Ciências da Saúde, Universidade Metodista de Piracicaba, Piracicaba - SP, Brazil \\ Ana O. de Souza \\ Instituto Butantan, São Paulo - SP, Brazil \\ Fabio C. S. Galetti and Célio L. Silva \\ Departamento de Bioquímica e Imunologia, Faculdade de Medicina de Ribeirão Preto, Universidade de São Paulo, Ribeirão \\ Preto - SP, Brazil \\ Marcio Silva, Eli F. Pimenta and Otavio Thiemann \\ Instituto de Física de São Carlos, Universidade de São Paulo, São Carlos - SP, Brazil \\ Michel R. Z. Passarini and Lara D. Sette \\ Divisão de Recursos Microbianos, Centro Pluridisciplinar de Pesquisas Químicas, Biológicas e Agrícolas, Universidade Estadual \\ de Campinas, CP 6171, 13083-970 Campinas - SP, Brazil \\ Recebido em 9/5/07; aceito em 30/11/07; publicado na web em 21/7/08
}

\begin{abstract}
Extracts obtained from 57 marine-derived fungal strains were analyzed by HPLC-PDA, TLC and ${ }^{1} \mathrm{H}$ NMR. The analyses showed that the growth conditions affected the chemical profile of crude extracts. Furthermore, the majority of fungal strains which produced either bioactive of chemically distinctive crude extracts have been isolated from sediments or marine algae. The chemical investigation of the antimycobacterial and cytotoxic crude extract obtained from two strains of the fungus Beauveria felina have yielded cyclodepsipeptides related to destruxins. The present approach constitutes a valuable tool for the selection of fungal strains that produce chemically interesting or biologically active secondary metabolites.
\end{abstract}

Keywords: marine-derived fungi; screening; Beauveria felina.

\section{INTRODUCTION}

Considering that the occurrence of fungi in the marine environment was first reported late in the nineteenth century ${ }^{1-4}$ and that the oceans cover more than $70 \%$ of the Earth's surface, the number of species of marine fungi which have been described is surprisingly much smaller than terrestrial species. This is because not only is marine mycology a recent science, but also because it seems to be inherently more difficult to access artificial media and growth conditions to isolate and to grow both new facultative and new obligate marine fungi. ${ }^{5-9}$

Obligate marine fungi have been defined either as capable of producing successive generations by sexual and asexual means in natural oceanic waters and oceans diluted by freshwater or on intertidal substrates ${ }^{5}$ or as those which grow and sporulate exclusively in a marine environment. On the other hand, facultative

*e-mail: rgsberlinck@iqsc.usp.br marine fungi are aquatic and terrestrial microorganisms that are able to grow in marine environments. ${ }^{10}$ Until 1991, only 321 species of obligate marine fungi had been described, ${ }^{11}$ the majority belonging to the class Ascomycete, which are found in shallow waters, frequently associated with marine algae, decomposing wood, ${ }^{7}$ crabs, fishes and sponges. ${ }^{11-13}$ Facultative marine fungi have been explored to a lesser extent, and only 56 species have been described until 1999. ${ }^{14}$

Recently, marine-derived fungi have been recognized as one of the last barely tapped sources for new biologically active secondary metabolites, ${ }^{2,6,8,11-13,15}$ including antitumor, antibacterial, antiviral, antifungal, anti-inflammatory and enzyme inhibitor compounds. ${ }^{16}$ This is probably because marine fungi have been explored to a much lesser extent than their terrestrial counterparts, which have been known for a long time as a very important source of biologically active and economically important natural products, such as those for use in treatment of human diseases as well as several others in biotechnological applications. ${ }^{17-19}$ 
We have recently started the first research program in Brazil towards the search for new biologically active secondary metabolites from marine bacteria and fungi. ${ }^{20,21}$ In order to establish a protocol to select strains capable of producing bioactive secondary metabolites, we envisaged a multi-screening approach using both biological and chemical methods for prioritizing extracts obtained from marine-derived fungi. The subsequent investigation of crude extracts obtained from two strains of Beauveria felina led to the isolation of a series of cyclodepsipeptides related to destruxins.

\section{EXPERIMENTAL}

\section{Marine fungi strains}

Fifty seven strains of marine-derived fungi were isolated from sediments, algae (Sargassum cymosum, Padina sp., Caulerpa sp. and an unidentified species of marine algae), one sponge (Tedania ignis) and one sea anemone (Anemonia sargassensis) (see Table 1), obtained at two locations: Cabelo Gordo de Fora beach, São

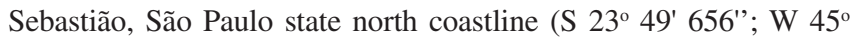
25' 351'); and Balneário beach, Peruíbe, São Paulo state south coastline (S 24' 19' 12"; W 46 59' 54"). Samples were processed as follows: Peruíbe sediment samples were collected with a sterilized spatula and preserved in sterilized culture tubes $(12 \mathrm{~mL})$ containing $10 \mathrm{~mL}$ of sterile sea water. After collection, the samples were maintained at $4{ }^{\circ} \mathrm{C}$ for transportation to laboratory. Marine invertebrate and algae samples were collected at São Sebastião with sterilized tweezers, while sediment samples were collected by immersion of closed sterilized tubes opening them underwater and the samples were immediately collected. Sediment samples were diluted $(1: 1,000,1: 10,000$ and 1:100,000) in sterilized sea water, followed by $200 \mu \mathrm{L}$ inoculation in Petri dishes containing MF culture medium ( $2 \%$ glucose, $1 \%$ soluble starch, $2 \%$ soytone, $0.5 \%$ peptone, $0.3 \%$ meat extract, $0.5 \%$ yeast extract, rifampicin $0.03 \%$, agar $1.5 \%$ in $100 \mathrm{~mL}$ sterilized sea water). Invertebrate and algae samples were also preserved in sterilized sea water. For fungal isolation, the biological samples (sponge, sea-anemone and algae) were strongly stirred with a vortex for one minute, and subsequently $200 \mu \mathrm{L}$ of each sample was inoculated in Petri dishes with MF medium. The inoculated samples were allowed to grow for 7 days at $25{ }^{\circ} \mathrm{C}$. Fungal isolates were obtained by exhaustive purification in Petri dishes and the purified strains were preserved in silica-gel in sealed eppendorfs ${ }^{22}$ at $4{ }^{\circ} \mathrm{C}$.

\section{Strain growth in artificial medium}

Each fungal strain was placed in two Pyrex culture tubes (12 $\mathrm{mL}$ ), containing $5 \mathrm{~mL}$ of $\mathrm{MF}$ agar and incubated at $25{ }^{\circ} \mathrm{C}$. After 7 days, a $0.85 \% \mathrm{NaCl}$ solution was added to each tube. Mycelia were scraped from the surface and each strain was transferred to a 500 $\mathrm{mL}$ Erlenmeyer flask containing $250 \mathrm{~mL}$ of MF broth. Each of the 57 isolates was grown in shaker culture and still culture. After fermentation, $250 \mathrm{~mL}$ of methylethylketone (butanone) was added to each of the 114 marine fungi samples that were cultured in MF medium.

\section{Chemical analysis of crude extracts}

Each sample obtained from the MF culture (liquid medium + mycelia + butanone mixture) was blended in a Waring-blender, and left overnight before filtering through a Whatman \#1 filter paper. The remaining solid residue was discarded. The filtrate was transferred to a separatory funnel, the organic layer collected, evaporated in vacuo, transferred to a small vial with $\mathrm{MeOH}$, and evaporated to dryness in a Speedvac system (Savant) and weighed. Aliquots of each crude extract were diluted with $\mathrm{MeOH}$ and analyzed by high performance liquid chromatography with a photodiode array detector (HPLC-PDA). Small aliquots of each crude extract were also prepared for thin layer chromatography (TLC) and for ${ }^{1} \mathrm{H}$ nuclear magnetic resonance ( ${ }^{1} \mathrm{H}$ NMR) analyses. HPLC-PDA analyses were performed with a Waters 717 autosampler, Waters 600 pump, Waters 2996 photodiode array detector monitored by Waters Millenium 32. The column used was a Waters $\mu$ Bondapak $\mathrm{C}_{18}$ reversed phase silica gel, $300 \times 7.8 \mathrm{~mm}$. Eluent: $100 \% \mathrm{H}_{2} \mathrm{O}$ for $1 \mathrm{~min}$, then a \#4 convex gradient curve for $25 \mathrm{~min}$ to $100 \% \mathrm{MeOH}$, and held at $100 \% \mathrm{MeOH}$ for $5 \mathrm{~min}$ at $1 \mathrm{~mL} / \mathrm{min}$.

TLC analyses were performed with Aldrich precoated silicagel plates with fluorescent UV indicator $(254 \mathrm{~nm})$. Each sample was applied in six separate plates. Three plates were eluted with a mixture of 1:1 hexanes-ethyl acetate (solvent \# 1), and 3 plates were eluted with 9:1 $\mathrm{CH}_{2} \mathrm{Cl}_{2}-\mathrm{MeOH}$ (solvent \# 2). After elution, all chromatographic plates were inspected under ultraviolet light $\left(\lambda_{\max }\right.$ $254 \mathrm{~nm}$ ). One of the plates eluted with solvent \#1 was sprayed with a solution of phosphomolybdic acid (5\% in EtOH), one with Dragendorff reagent and the last one with ninhydrin (5\% in EtOH). Plates eluted with solvent \#2 were subjected to the same procedure.

${ }^{1} \mathrm{H}$ NMR analyses were performed with a Bruker AC200 4.7 Tesla instrument, operating at $200.1 \mathrm{MHz}\left({ }^{1} \mathrm{H}\right)$. Approximately 10 $\mathrm{mg}$ of each sample was diluted in deuterated dimethylsulfoxide with TMS as an internal standard.

\section{Biological assays}

\section{Antibacterial activity}

Bacterial samples were prepared according to Nascimento et al.. ${ }^{23}$ Bacterial strains included: Pseudomonas aeruginosa (ATCC 27583), Escherichia coli (ATCC 259222), Staphylococcus aureus (ATCC 25923), Enterococcus faecalis (ATCC 29212), Salmomella cholaraesusis (ATCC 10708), and the yeast Candida albicans ATCC 10231. The following resistant strains, isolated at the Piracicaba city hospital, were also subjected to the antibacterial assay: E. coli \#9, E. cloacae, S. aureus \#8, S. aureus \#18, S. aureus \#68, S. aureus $\# 115$ and $S$. aureus \#134. Aliquots of $5 \mathrm{mg}$ of each fungal crude extract were subjected to the antibacterial bioassay following our previously reported procedure. ${ }^{24}$

\section{Antimycobacterial activity against Mycobacterium tuberculosis H37Rv}

The antimycobacterial activity of the crude extracts was determined according to standard reported procedures. ${ }^{3,25}$

\section{Inhibition of Leishmania tarentolae adenine phosphoribosyl- transferase (L-APRT)}

The inhibition of L-APRT was performed following a modified protocol described by Tuttle and Krenitsky. ${ }^{26}$

\section{Cytotoxicity assays}

HL-60 (leukemia), B16 (melanoma) and HCT8 (colon) cancer cell lines were obtained from Children's Mercy Hospital, Kansas City, MO. The microtiter assay for cytotoxicity was performed using the sulforhodamine B (SRB) method ${ }^{27}$ according to our previously described procedure. ${ }^{24}$

\section{Identification of fungal strains}

Preliminary identification of all strains was made by macro- 
and microscopic analysis. Beauveria felina strains AcSS8 and AcSS13 were identified by molecular and conventional methods, including DNA isolation, ITS amplification and subsequent sequencing. DNA were isolated following the method described by Raeder and Broda. ${ }^{4}$ The ITS1/ITS2 regions were amplified with the primers ITS 1 (5'-CCGTAGGTGAACCTGCGG-3') and ITS4 (5'-TCCTCCGCTTATTGATATGC-3'). Polymerase chain reaction DNA amplifications were performed in final reactions mixtures $(25 \mu \mathrm{L})$ containing 5-25 ng genomic DNA, $0.4 \mu \mathrm{M}$ of each primer, $0.2 \mu \mathrm{M}$ dNTPs (GE Healthcare), $1.5 \mu \mathrm{M} \mathrm{MgCl}_{2}$ (Invitrogen), $2.0 \mathrm{U}$ Taq polymerase (Invitrogen) and 1.0X reaction buffer (Invitrogen). Amplification reactions were performed in a PCR Sprint (Hybaid) with the following cycling conditions: initial denaturation for 5 min at $94{ }^{\circ} \mathrm{C}$ followed by 30 cycles of $30 \mathrm{~s}$ at $94{ }^{\circ} \mathrm{C}, 30 \mathrm{~s}$ at $55^{\circ} \mathrm{C}$ and $1 \mathrm{~min}$ at $72{ }^{\circ} \mathrm{C}$ with a final extension for $10 \mathrm{~min}$ at $72{ }^{\circ} \mathrm{C}$ and cooling to $4{ }^{\circ} \mathrm{C}$. Amplified products were purified, quantified and subjected to sequencing using the DYEnamic ET Dye Terminator Cycle Sequencing Kit for an automated MegaBace sequencer (GE Healthcare). The set of primers used for sequencing were ITS1 and ITS4.

Sequences were compared with ITS1/ITS2 sequence data from strains available in the public databases Genbank (http:// www.ncbi.nem.nih.gov) by using the BLAST N sequence match routines. The sequences were aligned using the CLUSTAL $X$ program and phylogenetic and molecular evolutionary analyses were conducted using MEGA version 2.0. ${ }^{28}$ The Kimura two-parameter model $^{29}$ was used to estimate evolutionary distance. The phylogenetic reconstruction was done using the neighbor-joining (NJ) algorithm, with bootstrap values calculated from 1,000 replicate runs, using the software routines included in the MEGA software.

After identificaton, Beauveria felina strains AcSS8 and AcSS13 were deposited at the Brazilian Collection of Microorganisms from Environment and Industry (CBMAI, Campinas, SP) under the numbers CBMAI 738 and CBMAI 739, respectively.

\section{RESULTS}

Among the 57 fungal strains isolated from the marine environment, 28 have been identified by morphological and biochemical analyses and are listed in Table 1S (Supplementary Material). We have been unable to identify twenty-nine strains of marine-derived fungi because these species did not sporulate in laboratory conditions. The majority of the identified strains belong to genera Penicillium (8 strains), Verticillium (5 strains), Aspergillus ( 2 strains) and Phoma (2 strains). Among the 57 strains of marinederived fungi obtained, 28 have been isolated from sediments and 21 from the marine algae Padina sp., Caulerpa sp., Sargassum cymosum and one unidentified alga species. One fungal strain was isolated from the sponge Tedania ignis and 3 from the sea-anemone Anemonia sargassensis (Table 1S). All marine-derived fungi studied in the present work were grown both in saline and salt-free media, and results showed that 14 strains grew exclusively in saline medium (Table 1S).

All fungal strains were grown in MF medium in two different conditions: dynamic (shaking at $200 \mathrm{rpm}, 7$ days) and still mode (30 days). Crude extracts were obtained from each strain grown in both conditions. Crude extracts obtained from strains which were grown dynamically presented less mass quantity than crude extracts obtained from the medium of strains which were grown under still conditions. Not only the quantity of the organic crude extract obtained from each strain was different when it was grown in the two conditions, but also the chemical composition was different, as observed by
HPLC-PDA, TLC and ${ }^{1} \mathrm{H}$ NMR analyses, as well as by the bioassays results (Tables $1 \mathrm{~S}$ and $2 \mathrm{~S}$, Supplementary Material).

TLC analyses of all 114 crude extracts indicated that 12 extracts presented nitrogen-bearing compounds (revealed by Dragendorff reagent, Table 1S). These included Phoma sp. (S2SS4), Beauveria felina (AcSS13), Rhinocladiella sp. 2 (AdSSP15), Pestalotiopsis sp. (SP51), and the unidentified strains S3SS5, AaSS17, S1SS23, S1SS25, AaSS27, S2SS32, S1SS34, and SP56. All crude extracts were also analyzed by HPLC-PDA, and the results showed that only twenty presented a distinctive chromatographic pattern (Table 1S), with peaks showing UV absorptions with $\lambda_{\text {max }}$ above $250 \mathrm{~nm}$, characteristic of conjugated systems. Among these, 11 were obtained from fungi grown under still conditions and 9 under shaking; 12 were obtained from fungi isolated from marine sediments, 6 from marine algae, 1 from the sea anemone $A$. sargassensis and 1 from the sponge T. ignis. Crude extracts obtained from Penicillium sp. 5 (ESS41) isolated from T. ignis, as well as from Penicillium sp. (AcSS53), and Penicillium sp. 8 (AcSS54) isolated from the alga Caulerpa sp. presented the richest chemical profiles, indicated by the number of peaks in the chromatograms with distinctive UV absorptions. The twenty crude extracts selected by HPLC-PDA were subjected to ${ }^{1} \mathrm{H}$ NMR analysis. The ${ }^{1} \mathrm{H}$ NMR spectra showed several signals indicating the presence of aromatic and/or unsaturated groups, as well as oxygen- and/or nitrogencontaining functional groups.

The 114 crude extracts from derived-marine-fungi were also submitted to four bioassays: antibacterial activity against common and resistant strains of human pathogenic bacteria and against Mycobacterium tuberculosis $\mathrm{H} 37 \mathrm{Rv}$; antifungal activity against Candida albicans; inhibition of the enzyme adenine phosphoribosyl transferase of Leishmania tarentolae (L-APRT); as well as cytotoxic activity against human cancer cell lines (Table 2S). None of the crude extracts displayed inhibitory activity against L-APRT. Eleven of the crude extracts displayed antimycobacterial activity against M. tuberculosis H37Rv. Twenty three extracts of the marinederived fungi displayed antibacterial activity: one against $P$. aeruginosa, 1 against antibiotic-resistant E. coli, 1 against antibiotic-sensitive E. coli, 10 against $S$. aureus of which 1 (Phoma sp., S2SS24) exhibited disc inhibition zones higher than $20 \mathrm{~mm}$, 10 extracts displayed activity against different strains of antibacterial resistant $S$. aureus, 1 against $E$. faecalis, 1 against $S$. choleraesusis and 1 against antibacterial resistant strain of E. cloacae. In addition, 3 marine-derived fungal strains yielded crude extracts with strong antifungal activity against C. albicans: Verticillium sp. 5 (AcSS52), Penicillium sp. (AcSS53) and SP56. Finally, 14 marine-derived fungal strains yielded crude extracts which displayed considerable anti-proliferative activity against 1 or more of the tumor cell lines (Table 2S), 6 of them with potent cytotoxic activity: Beauveria felina (AcSS8 and AcSS13), Penicillium sp. 2 (CSS19), strain S2SS24, Verticillium sp. 1 (S1SS30) and strain S1SS31 (Table 2S).

The results of chemical (HPLC-PDA and TLC) and bioassay (antimycobacterial, antibacterial, anti-fungal and cytotoxic) screenings were all combined in order to obtain additional information to reveal strains that produced bioactive secondary metabolites (Tables 3S and 4S). Results obtained from the HPLCPDA analyses showed that the growth mode (shaken or still) had only partial influence on the chemical profile of the crude extracts, since the number of crude extracts with distinctive chromatograms/ UV absorptions was practically equal for fungi grown either in still or dynamic conditions. The same observation was true for extracts which presented nitrogen-bearing compounds and antibacterial activity. However, only crude extracts obtained from fungi which were grown in still mode displayed antifungal activity 
against $C$. albicans and cytotoxic activity, with one exception. The majority of marine-derived fungal strains which yielded crude extracts with either an interesting chemical profile, nitrogen-bearing compounds, antibacterial, antifungal and cytotoxic activities were strains isolated from either sediments or marine algae (Table 3S).

We subsequently selected the crude extracts of fungal strains AcSS8 and AcSS13 for chemical investigation, since the crude extract of AcSS8 presented a single peak with distinctive UV absorption above $\lambda_{\text {max }} 280 \mathrm{~nm}$, the crude extract of AcSS13 displayed positive Dragendorff reaction and both extracts presented cytotoxicity and antimycobacterial activities. Data derived from taxonomic analyses showed that these two strains belong to the same species and were identified by conventional and molecular taxonomy as Beauveria felina. Both extracts were obtained in sufficient quantity for chemical fractionation by silica-gel chromatography followed by HPLC purification. The crude extract obtained from AcSS-8 strain yielded eight cyclodepsi-peptides $(\mathbf{1}-\mathbf{8})$ related to destruxins. ${ }^{30,31}$ All compounds were identified by analysis of LC-MS, ${ }^{1} \mathrm{H}$ NMR, ${ }^{13} \mathrm{C}$ NMR, COSY ${ }^{1} \mathrm{H}-{ }^{-1} \mathrm{H}$, HSQC, HMBC, TOCSY, high-resolution mass spectrometry and comparison with literature data. ${ }^{30}$

\section{DISCUSSION}

Marine-derived fungi are considered a remarkable source of biologically active natural products with new chemical structures. ${ }^{2,6,12,13}$ Therefore, it is of interest to develop different approaches for the discovery of marine-derived fungal species that produce biologically active secondary metabolites.

In the present investigation, 57 marine-derived fungi strains have been isolated from sediments, algae and invertebrates (Table 1S). Fungal samples obtained from sediments or algae yielded crude extracts with the richest chemical profile, as indicated by both chemical and biological screenings. These fungi are likely to produce bioactive secondary metabolites, corroborating the results presented in the literature. . $^{612-14}$

The isolation of only 4 fungal strains from marine invertebrates during the present investigation may be a reflection that fungi are not usually present in sponge tissues. ${ }^{12}$ However, Höller et al. ${ }^{13}$ have been able to isolate more than 600 marine fungi strains from tissues of marine sponges, Pivkin et al. ${ }^{14}$ isolated 38 marine fungi strains from marine invertebrates, and Bernan et al. ${ }^{11}$ isolated 78 fungi strains from marine invertebrates. Consequently, it seems reasonable to suppose that isolation of fungal strains from different marine sources depends largely on the isolation and growth procedures.

Although natural products isolated from marine-derived fungi have been shown to present quite diverse chemotypes, only a few of them were isolated from obligate marine strains. ${ }^{16}$ This may be a direct consequence of methods used for strain isolation, which in many instances are not adequate for the isolation or growth of obligate marine fungal strains. ${ }^{6,12}$ Although in the past Kohlmeyer and Kohlmeyer ${ }^{10}$ defined marine fungi as those species able to grow and sporulate exclusively in the marine environment, it has recently been suggested that this feature seems to be growth restrictive even for obligate marine strains. ${ }^{12}$ On the other hand, facultative marinederived strains such as Aspergillus, Penicillium, Verticillium and Phoma present a high degree of salinity tolerance and, therefore, are frequently isolated ${ }^{12}$ and produce bioactive extracts and compounds. ${ }^{6,11,13,14}$ Since the structural novelty of natural products isolated from marine-derived fungi increases with species diversification, it is also of interest to employ different methods for isolation and growth of obligate marine or taxonomically rare fungal strains..$^{6,7}$
Results from growth conditions showed that 14 strains grew exclusively in saline media (Table $1 \mathrm{~S}$ ), suggesting that these may belong to the group of obligate marine fungi. However, additional experiments on these strains must be performed, including taxonomic identification, in order to confirm a true origin.

We also observed that fungal strains grown with shaking yielded less quantity of crude extract than fungi grown under still conditions. This may be a consequence of the longer period of growth (30 days) under still conditions. However, less exposure to aerobic conditions seems to favour the production of secondary metabolites by marine fungi under still conditions. Not only the quantity of the organic crude extract obtained from each fungal species was different when the same strain was grown in the two conditions, but also the chemical composition was different, as observed by HPLC-PDA, TLC and ${ }^{1} \mathrm{H}$ NMR analyses, as well as by the bioassays results (Tables $1 \mathrm{~S}$ and $2 \mathrm{~S}$ ). Therefore, marine-derived fungi appear to be highly sensitive to changes in growth conditions. ${ }^{6,7,13}$ Therefore, it would be of interest to explore variation in medium composition and growth conditions of fungi strains which appear to produce secondary metabolites in order to enhance the production of natural products both in quantity and variety. According to Bugni and Ireland, ${ }^{6}$ fungal metabolite production may be enhanced in higher ionic concentrations, such as those found in ASW (artificial seawater).

None of the crude extracts displayed inhibitory activity against L-APRT. This result may be indicative of the bioassay specificity since this is an enzyme-based assay that requires much more specific active-site binding inhibitors.

In crossing the results obtained from this multi-screening, we observed some interesting features for crude extracts, which presented simultaneous chemically and biologically positive results. Marine fungal strains grown under still conditions seem to produce bioactive secondary metabolites more frequently, as shown in Table 4S (Supplementary Material). For example, 7 crude extracts obtained from fungi grown under still conditions displayed both antibacterial and cytotoxic activities. The majority of strains which yielded crude extracts that presented metabolites detected in two or three chemical and/or biological analyses simultaneously were isolated from either sediments or marine algae. We also observed that only a few fungal strains yielded crude extracts which presented positive results in two simultaneous screening criteria, and even a smaller number with positive results in three simultaneous screening criteria (Table 4S). Such features are of special interest for the selection of marine-derived fungal strains that produce chemically interesting and biologically active natural products.

Based on their cytotoxic and antimycobacterial activities and chemical profile, crude extracts obtained from Beauveria felina strains AcSS8 and AcSS13 were selected for a chemical investigation. We have been able to isolate eight cyclodepsipeptides: the new pseudodestruxin $\mathrm{C}(\mathbf{1})$ and $\beta$-Me-Pro destruxin $\mathrm{E}$ chlorohydrin $(2),{ }^{30}$ along with the known $\left[\mathrm{Ph}^{3}, N-\mathrm{Me}-\mathrm{Val}^{5}\right]$ destruxin B (3), destruxin E chlorohydrin (4), roseotoxin B (5), roseocardin (6), isariin (7) and isariin B (8). ${ }^{30,31}$ Destruxins are a well known class of cyclic depsipeptides ${ }^{31}$ that present an array of biological activities such as insecticidal, cytotoxic, antiviral, immunodepressant and phytotoxic. This is the first report of destruxin derivatives from a marine-derived fungus associated with a marine alga (Caulerpa sp.). The majority of these peptides have been isolated from Metarrhizium anisopliae. ${ }^{31}$ The isolation of the cyclodepsipeptides $\mathbf{1}-\mathbf{8}$ from two strains of B. felina isolated from the alga Caulerpa sp. constitute a validity for the multi-screening herein reported. The choice of $B$. felina crude extracts was based on three screening criteria: bioactivity, positive response to the 
<smiles></smiles><smiles>CCC(C)C(NC(=O)C1[C@H](C)CCN1C(=O)C(CC(O)CCl)OC(=O)CCNC(=O)C(C)N(C)C(=O)C(C)C)C(C)C</smiles><smiles>CC(C)C[C@H]1OC(=O)CCNC(=O)[C@H](C(C)C)N(C)C(=O)[C@H](C(C)C)N(C)C(=O)[C@H](Cc2ccccc2)NC(=O)[C@@H]2CCCN21</smiles><smiles>CCC(C)C(NC(=O)C1CCCN1C(=O)C(CC(O)CCl)OC(=O)CCNC(=O)C(C)N(C)C(=O)C(C)C)C(C)C</smiles>

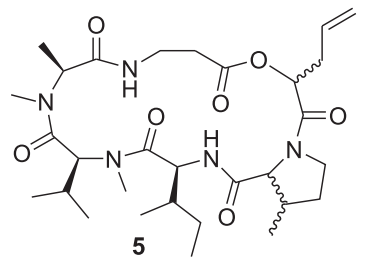<smiles>CCC(C)C(NC(=O)C1[C@H](C)CCN1C(=O)[C@@H](CC(C)C)OC(=O)CCNC(=O)C(C)N(C)C(=O)C(C)C)C(C)C</smiles>

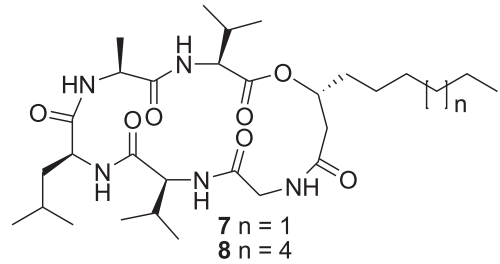

Dragendorff reagent and distinctive UV absorption of a single peak in the HPLC-PDA analysis.

In conclusion, the present study demonstrated that a multiscreening approach, including both chemical and bioassay analyses of crude extracts, is a helpful tool for the selection of marine-derived fungal strains that present an active secondary metabolism, suitable for the production of biologically active natural products, as demonstrated by the isolation of biologically active cyclic depsipeptides related to destruxins.

Since some of the marine-derived fungi isolated and analyzed herein produced antimycobacterial, antibacterial, antinfungal, and/ or antitumor extracts, these strains can be considered as attractive for further studies on the isolation and identification of bioactive compounds, as well as for additional taxonomic analyses involving a polyphasic approach in order to assign specific species identification.

\section{SUPPLEMENTARY MATERIAL}

Tables $1 \mathrm{~S}, 2 \mathrm{~S}, 3 \mathrm{~S}$ and $4 \mathrm{~S}$. This material is available at http:// www.quimicanova.sbq.org.br, in PDF file.

\section{ACKNOWLEDGMENTS}

The authors thank M. K. Harper (Department of Medicinal Chemistry, University of Utah) for the manuscript revision, to Prof. J. C. de Freitas (Instituto de Biociências, Universidade de São Paulo) for identification of marine algae and invertebrates, and also to Prof $^{a}$ E. Trajano, director of the Centro de Biologia Marinha of Universidade de São Paulo, for providing many facilities during the collection of biological samples. Financial support provided by FAPESP and NIH-NCI NCDDG grants, as well as scholarships from CAPES and CNPq, are gratefully acknowledged.

\section{REFERENCES}

1. Johnson, T. W.; Sparrow, F. K.; Fungi in Oceans and Estuaries, $1^{\text {st }}$ ed., Cramer \& Hafner Pub. Co.: New York, 1961.

2. Liberra, K.; Lindequist, U.; Pharmazie 1995, 50, 583.

3. Oliveira, M. F.; Oliveira, J. H. H. L.; Galetti, F. C. S.; Souza, A. O.; Silva, C. L.; Hajdu, E.; Peixinho, S.; Berlinck, R. G. S.; Planta Med. 2006, 72, 437.

4. Raeder, J.; Broda, P.; J. Appl. Microbiol. 1985, 1, 17.

5. Booth, T.; Rev. Microbiol. (S. Paulo) 1979, 10, 123.

6. Bugni, T. S.; Ireland, C. M.; Nat. Prod. Rep. 2004, 21, 143.

7. Fenical, W.; Jensen, P. R. In Marine Biotechnology: Pharmaceutical and Bioactive Natural Products; Attaway, D. H.; Zaborsky, O. R.; eds.; Plenum Press: New York and London, 1983, p. 419-457.

8. Pietra, F.; Nat. Prod. Rep. 1997, 14, 453.

9. Wang, G.; J. Ind. Microbiol. Biotechnol. 2006, 33, 545

10. Kohlmeyer, J.; Kohlmeyer, E.; Marine Mycology: The Higher Fungi, $1^{\text {st }}$ ed., Academic Press: New York, 1979.

11. Bernan, V. S.; Greenstein, M.; Maiese, W. M.; Adv. Appl. Microbiol. 1997, $43,57$.

12. Fenical, W.; Jensen, P. R.; Hyde, K. D.; Fungal Div. Res. Ser. 2002, 7, 293.

13. Höller, U.; Wright, A. D.; Matthee, G. F.; König, G. M.; Draeger, S.; Aust, H. J.; Schulz, B.; Mycol. Res. 2000, 104, 1354.

14. Pivkin, M. V.; Afiyatullov, S. S.; Elyakov, G. B. In Biodiversity and Allelopathy: From Organisms to Ecosystems in the Pacific; Chou, C. H.; Waller, G. A.; Reinhardt, C., eds.; Academica Sinica: Taipei, 1999, chapter 3.

15. Biabani, M. A. F.; Laatsch, H.; J. Prakt. Chem./Chem.-Ztg. 1998, 340, 589.

16. Kelecom, A.; An. Acad. Bras. Ciênc. 2002, 74, 151

17. Bennet, J. W.; J. Biotechnol. 1998, 66, 101.

18. Strobel, G. A.; Crit. Rev. Biotech. 2002, 22, 315.

19. Tan, R. X.; Zou, W. X.; Nat. Prod. Rep. 2001, 18, 448.

20. Hernandez, I. L. C.; Godinho, M. J. L.; Magalhães, A.; Schefer, A. B.; Ferreira, A. G.; Berlinck, R. G. S.; J. Nat. Prod. 2000, 63, 664.

21. Hernandez, I. L. C.; Camargo, G. S. P.; Macedo, M. L.; Berlinck, R. G. S.; Ferreira, A. G.; Godinho, M. J. L.; J. Braz. Chem. Soc. 2004, 15, 441.

22. Grivell, A. R.; Jackson, J. F.; J. Gen. Appl. Microbiol. 1969, 58, 423.

23. Nascimento, G. G. F.; Locatelli, J.; Freitas, P. C.; Silva, G. L.; Braz. J. Microbiol. 2000, 31, 247.

24. Torres, Y. R.; Berlinck, R. G. S.; Nascimento, G. G. F.; Fortier, S. C.; Pessoa, C.; Moraes, M. O.; Toxicon 2002, 40, 885.

25. Collins, L. A.; Franzblau, S. G.; Antimicrob. Agents Chemother. 1997, 41, 1004.

26. Tuttle, J. V.; Krenitsky, T. A.; J. Biol. Chem. 1980, 255, 909.

27. Skehan, P.; Storeng, R.; Scudiero, D.; Monks, A.; McMahon, J.; Vistica, D.; Warren, J. T.; Bodesch, H.; Kenney, S.; Boyd, M. R.; J. Nat. Canc. Inst. 1990, 82, 1107.

28. Kumar, S.; Tamura, K.; Jakobsen, I. B.; Nei, M.; Bioinform. 2001, 17,1244. 29. Kimura, M.; J. Mol. Evol. 1980, 16, 111.

30. Lira, S. P.; Vita-Marques, A. M.; Seleghim, M. H. R.; Bugni, T. S.; LaBarbera, D.; Sette, L. D.; Sponchiado, S. R. P.; Irleland, C. M.; Berlinck, R. G. S.; J. Antibiot. 2006, 59, 553.

31. Pedras, M. S. C.; Zaharia, L. I.; Ward, D. E.; Phytochemistry 2002, 59, 579. 


\section{A MULTI-SCREENING APPROACH FOR MARINE-DERIVED FUNGAL METABOLITES AND THE ISOLATION OF CYCLODEPSIPEPTIDES FROM Beauveria felina}

Aline Maria de Vita-Marques, Simone P. Lira and Roberto G. S. Berlinck*

Instituto de Química de São Carlos, Universidade de São Paulo, CP 780, 13560-970 São Carlos - SP, Brazil

Mirna H. R. Seleghim

Departamento de Ecologia e Biologia Evolutiva, Universidade Federal de São Carlos, São Carlos - SP, Brazil

Sandra R. P. Sponchiado

Departamento de Bioquímica e Tecnologia Química, Universidade Estadual Paulista, Araraquara - SP, Brazil

Sâmia M. Tauk-Tornisielo

Centro de Estudos Ambientais, Universidade Estadual Paulista, Av. 24-A, 1515, 13506-900 Rio Claro - SP, Brazil

Margarida Barata

Departamento de Biologia Vegetal (Microbiologia), Centro de Biologia Ambiental, Faculdade de Ciências de Lisboa, Lisboa, Portugal

Claudia Pessoa, Manoel O. de Moraes and Bruno Coêlho Cavalcanti

Departamento de Fisiologia e Farmacologia, Universidade Federal do Ceará, Fortaleza - CE, Brazil

Gislene G. F. Nascimento

Faculdade de Ciências da Saúde, Universidade Metodista de Piracicaba, Piracicaba - SP, Brazil

Ana O. de Souza

Instituto Butantan, São Paulo - SP, Brazil

Fabio C. S. Galetti and Célio L. Silva

Departamento de Bioquímica e Imunologia, Faculdade de Medicina de Ribeirão Preto, Universidade de São Paulo, Ribeirão Preto - SP, Brazil

Marcio Silva, Eli F. Pimenta and Otavio Thiemann

Instituto de Física de São Carlos, Universidade de São Paulo, São Carlos - SP, Brazil

Michel R.Z. Passarini and Lara D. Sette

Divisão de Recursos Microbianos, Centro Pluridisciplinar de Pesquisas Químicas, Biológicas e Agrícolas, Universidade Estadual de Campinas, CP 6171, 13083-970 Campinas - SP, Brazil

Table 1S. Identification*, origin and growth media of the 57 strains of marine fungi, as well as the growth mode of marine-derived fungal strains which yielded crude extracts with a distinctive chemical profile analyzed by HPLC-PDA and TLC

\begin{tabular}{|c|c|c|c|c|c|c|}
\hline \multirow[t]{2}{*}{ Fungi strain } & \multirow[t]{2}{*}{ Origin } & \multicolumn{2}{|c|}{$\begin{array}{l}\text { MF Culture } \\
\text { medium }\end{array}$} & \multirow[t]{2}{*}{$\begin{array}{l}\text { Growth } \\
\text { mode }\end{array}$} & \multirow{2}{*}{$\begin{array}{l}\text { HPLC-PDA } \\
\text { distinctive } \\
\text { (\# of peaks) }\end{array}$} & \multirow{2}{*}{$\begin{array}{c}\text { TLC } \\
\text { (Dragendorff) }\end{array}$} \\
\hline & & saline & salt-free & & & \\
\hline Unidentified fungus $\mathbf{S 4 S S 1}$ & Sediment & + & - & & & \\
\hline Hansfordia ovalispora S4SS2 & Sediment & + & + & $\mathrm{D}$ & $+(1)$ & - \\
\hline Unidentified fungus AbSS3 & Padina sp. & + & - & & & \\
\hline Phoma sp. 1 S2SS4 & Sediment & + & + & $\mathrm{D}$ & $+(1)$ & + \\
\hline Unidentified fungus S3SS5 & Sediment & + & - & $\mathrm{D}$ & $+(2)$ & + \\
\hline Unidentified fungus S4SS6 & Sediment & + & - & $\mathrm{D}$ & $+(1)$ & - \\
\hline Spadicoides sp. 1 S4SS7 & Sediment & + & - & $\mathrm{D}$ & $+(1)$ & - \\
\hline Beauveria felina AcSS8 & Caulerpa sp. & + & + & $\mathrm{D}$ & $+(1)$ & - \\
\hline Unidentified fungus AcSS9 & Caulerpa sp. & + & + & $\mathrm{D}$ & $+(1)$ & - \\
\hline Unidentified fungus AcSS10 & Caulerpa sp. & + & + & & & \\
\hline Unidentified fungus S4SS11 & Sediment & + & + & & & \\
\hline Rhinocladiella sp. AcSS12 & Caulerpa sp. & + & - & $\mathrm{S}$ & $+(1)$ & - \\
\hline Beauveria felina AcSS13 & Caulerpa sp. & + & + & $\mathrm{D}$ & - & + \\
\hline Phoma sp. 2 AcSS14 & Caulerpa sp. & + & - & & & \\
\hline Rhinocladiella sp. 2 Ad(SS)P15 & Unidentified algae & + & - & $\mathrm{D}$ & - & + \\
\hline Penicillium sp. 1 S2SS16 & Sediment & + & + & $\mathrm{S}$ & $+(1)$ & - \\
\hline Unidentified fungus AaSS17 & Sargassum cymosum & + & + & $\mathrm{S}$ & - & + \\
\hline Unidentified fungus CSS18 & Anemonia sargassensis & + & + & & & \\
\hline Penicillium sp. 2 CSS19 & Anemonia sargassensis & + & + & $\mathrm{S}$ & $+(1)$ & - \\
\hline Unidentified fungus S2SS20 & Sediment & + & - & & & \\
\hline Penicillium sp. 3 S1SS21 & Sediment & + & + & & & \\
\hline Spadicoides sp. AbSS22 & Padina sp. & + & + & & & \\
\hline Unidentified fungus S1SS23 & Sediment & + & + & $\mathrm{D}$ & - & + \\
\hline Unidentified fungus S2SS24 & Sediment & + & + & & & \\
\hline
\end{tabular}

*e-mail: rgsberlinck@iqsc.usp.br 
Table 1S.

\begin{tabular}{|c|c|c|c|c|c|c|}
\hline \multirow[t]{2}{*}{ Fungi strain } & \multirow[t]{2}{*}{ Origin } & \multicolumn{2}{|c|}{$\begin{array}{l}\text { MF Culture } \\
\text { medium }\end{array}$} & \multirow[t]{2}{*}{$\begin{array}{l}\text { Growth } \\
\text { mode }\end{array}$} & \multirow{2}{*}{$\begin{array}{l}\text { HPLC-PDA } \\
\text { distinctive } \\
\text { (\# of peaks) }\end{array}$} & \multirow{2}{*}{$\begin{array}{c}\text { TLC } \\
\text { (Dragendorff) }\end{array}$} \\
\hline & & saline & salt-free & & & \\
\hline Unidentified fungus S1SS25 & Sediment & + & + & $\mathrm{S}$ & - & + \\
\hline Curvularia borreriae RP26 & Rock & + & + & & & \\
\hline Unidentified fungus AaSS27 & Sargassum cymosum & + & + & $\mathrm{S}$ & - & + \\
\hline Unidentified fungus S1SS28 & Sediment & + & - & & & \\
\hline Penicillium sp. 4 AbSS29 & Padina sp. & + & + & & & \\
\hline Penicillium sp. 1 S1SS30 & Sediment & + & + & & & \\
\hline Unidentified fungus S1SS31 & Sediment & + & + & $\mathrm{D}$ & $+(1)$ & - \\
\hline Unidentified fungus $\mathbf{S 3 S S 3 2}$ & Sediment & + & + & $\mathrm{S}$ & - & + \\
\hline Unidentified fungus $\mathbf{S 2 S S 3 3}$ & Sediment & + & + & & & \\
\hline Unidentified fungus S1SS34 & Sediment & + & + & $\mathrm{S}$ & - & + \\
\hline Unidentified fungus AaSS35 & Sargassum cymosum & + & - & & & \\
\hline Verticillium sp. 2 AaSS36 & Sargassum cymosum & + & + & & & \\
\hline Unidentified fungus CSS37 & Anemonia sargassensis & + & + & & & \\
\hline Verticillium sp. 3 S3SS38 & Sediment & + & + & $\mathrm{S}$ & $+(2)$ & - \\
\hline Verticillium sp. 4 SP39 & Sediment & + & + & & & \\
\hline Spadicoides sp. 2 AbSS40 & Padina sp. & + & + & $\mathrm{S}$ & $+(2)$ & - \\
\hline Penicillium sp. 5 ESS41 & Tedania ignis & + & + & $\mathrm{S}$ & $+(4)$ & - \\
\hline Penicillium sp. 6 AbSS42 & Padina sp. & + & + & & & \\
\hline Aspergillus sp. 1 SP43 & Sediment & + & - & & & \\
\hline Aspergillus sp. 2 SP44 & Sediment & + & + & & & \\
\hline Penicillium sp. 7 RP45 & Rock & + & + & & & \\
\hline Unidentified fungus AbSS46 & Padina sp. & + & + & & & \\
\hline Unidentified fungus SP47 & Sediment & + & + & $\mathrm{S}$ & $+(2)$ & - \\
\hline Unideitnfied fungus RP48 & Rock & + & - & & & \\
\hline Unidentified fungus RP49 & Rock & + & + & & & \\
\hline Unidentified fungus SP50 & Sediment & + & + & $\mathrm{S}$ & $+(1)$ & - \\
\hline Unidentified fungus SP50 & Sediment & + & + & $\mathrm{D}$ & $+(1)$ & - \\
\hline Pestalotiopsis sp. 1 SP51 & Sediment & + & + & $\mathrm{S}$ & $+(2)$ & + \\
\hline Verticillium sp. 5 AcSS52 & Caulerpa sp. & + & + & & & \\
\hline Penicillium sp. AcSS53 & Caulerpa sp. & + & + & $\mathrm{S}$ & $+(4)$ & - \\
\hline Penicillium sp. 8 AcSS54 & Caulerpa sp. & + & + & $\mathrm{S}$ & $+(3)$ & - \\
\hline Pestalotiopsis sp. 2 SP55 & Sediment & + & - & & & \\
\hline Unidentified fungus SP56 & Sediment & + & + & $\mathrm{S}$ & - & + \\
\hline Unidentified fungus AaSS57 & Sargassum cymosum & + & + & & & \\
\hline
\end{tabular}

*Alpha-numerical codes refer to the authors fungal sample repository, where voucher samples of all fungal strains have been deposited; D: growth in dynamic mode with shaking at $200 \mathrm{rpm}$; S: growth in still mode. 
Table 2S. Antimycobacterial, antibiotic, antifungal and cytotoxic activities of crude extracts obtained from marine fungi strains

\begin{tabular}{|c|c|c|c|c|c|c|c|c|c|c|c|c|c|c|c|c|c|}
\hline \multirow{2}{*}{$\begin{array}{l}\text { FUNGI } \\
\text { STRAIN }\end{array}$} & \multirow{2}{*}{$\begin{array}{c}\text { GROWTH } \\
\text { MODE }\end{array}$} & \multicolumn{13}{|c|}{ MICROORGANISMS } & \multicolumn{3}{|c|}{ cell lines } \\
\hline & & 1 & 2 & 3 & 4 & 5 & 6 & 7 & 8 & 9 & 10 & 11 & 12 & 13 & $\mathrm{~A}$ & $\mathrm{~B}$ & $\mathrm{C}$ \\
\hline S4SS2 & $\mathrm{S}$ & - & - & - & - & - & + & - & - & - & - & - & - & - & - & - & - \\
\hline S2SS4 & $\mathrm{S}$ & +++ & - & - & - & - & - & - & - & - & - & - & - & - & - & - & - \\
\hline \multirow[t]{2}{*}{ S3SS5 } & $\mathrm{D}$ & - & - & - & - & + & - & - & - & - & - & - & - & - & - & - & - \\
\hline & $\mathrm{S}$ & - & - & - & - & - & - & - & - & - & - & - & - & - & - & - & - \\
\hline S4SS6 & $\mathrm{D}$ & + & - & - & - & - & - & - & - & - & - & - & - & - & - & - & - \\
\hline \multirow[t]{2}{*}{ AcSS8 } & D & - & + & - & - & - & - & - & - & - & - & - & - & - & - & - & - \\
\hline & $\mathrm{S}$ & ++ & - & - & - & - & - & - & - & - & - & - & - & - & ++ & +++ & ++ \\
\hline AcSS9 & $\mathrm{S}$ & - & - & - & - & + & - & - & - & - & - & - & - & - & - & - & - \\
\hline AcSS12 & $\mathrm{S}$ & - & - & - & - & - & - & - & - & - & - & - & - & - & - & - & + \\
\hline \multirow[t]{2}{*}{ AcSS13 } & D & - & - & - & - & - & - & - & - & - & - & - & - & - & - & - & + \\
\hline & $\mathrm{S}$ & ++ & - & - & - & - & - & - & - & - & - & - & - & - & + & +++ & ++ \\
\hline AdP15 & $\mathrm{S}$ & - & - & - & - & - & - & - & - & - & - & - & - & - & + & ++ & ++ \\
\hline S2SS16 & $\mathrm{S}$ & - & - & - & - & - & - & - & - & - & - & - & ++ & - & - & + & ++ \\
\hline \multirow{2}{*}{ CSS19 } & $\mathrm{D}$ & - & - & - & - & - & - & - & + & - & - & - & - & - & - & - & - \\
\hline & $\mathrm{S}$ & - & - & - & - & - & - & - & - & - & - & - & - & - & + & + & +++ \\
\hline AbSS22 & $\mathrm{D}$ & + & - & - & - & - & - & - & - & + & ++ & - & - & - & - & - & - \\
\hline S1SS23 & $\mathrm{D}$ & - & - & - & - & + & - & - & - & - & - & - & - & - & - & - & - \\
\hline \multirow[t]{2}{*}{ S2SS24 } & $\mathrm{D}$ & - & - & - & - & +++ & - & - & - & - & - & - & - & - & - & - & - \\
\hline & $\mathrm{S}$ & - & - & - & - & - & - & - & - & - & - & - & - & - & ++ & ++ & ++ \\
\hline S1SS25 & $\mathrm{S}$ & ++ & - & - & - & - & - & - & - & - & - & - & - & - & - & ++ & + \\
\hline RP26 & $\mathrm{D}$ & - & - & - & - & - & - & - & - & - & - & - & + & - & - & - & - \\
\hline S1SS28 & $\mathrm{S}$ & - & - & - & - & - & - & - & - & - & - & - & - & - & - & + & - \\
\hline AbSS29 & $\mathrm{D}$ & ++ & - & - & - & - & - & - & - & - & - & - & - & - & - & - & - \\
\hline S1SS30 & $\mathrm{S}$ & +++ & - & - & - & - & - & - & - & - & - & - & - & - & + & +++ & +++ \\
\hline S1SS31 & $\mathrm{S}$ & - & - & - & - & - & - & - & - & - & - & - & - & - & + & ++ & +++ \\
\hline S3SS32 & $\mathrm{S}$ & - & - & - & - & - & - & + & - & + & - & - & - & - & - & + & + \\
\hline S2SS33 & $\mathrm{S}$ & ++ & - & - & - & - & - & - & - & - & - & - & - & - & - & + & - \\
\hline AaSS35 & $\mathrm{D}$ & - & - & - & - & + & - & - & - & - & - & - & - & - & - & - & - \\
\hline S3SS38 & $\mathrm{S}$ & - & - & - & - & - & - & - & - & - & - & - & - & - & - & + & + \\
\hline SP43 & $\mathrm{D}$ & - & - & - & - & - & - & - & - & - & - & + & - & - & - & - & - \\
\hline SP44 & D & - & - & - & - & - & - & - & + & + & - & - & - & - & - & - & - \\
\hline RP45 & $\mathrm{D}$ & - & - & - & - & - & + & - & - & - & - & - & + & - & - & - & - \\
\hline AbSS46 & $\mathrm{D}$ & - & - & - & - & + & - & - & - & - & - & - & - & - & - & - & - \\
\hline SP47 & $\mathrm{S}$ & - & - & - & - & + & - & - & - & - & - & - & - & - & - & - & - \\
\hline RP49 & $\mathrm{D}$ & - & - & - & - & + & - & - & - & + & - & - & - & - & - & - & - \\
\hline AcSS52 & $\mathrm{S}$ & - & - & - & - & + & - & - & - & - & - & - & - & +++ & - & - & - \\
\hline AcSS53 & $\mathrm{S}$ & - & - & - & - & + & - & - & - & - & - & - & - & +++ & - & - & - \\
\hline AcSS54 & $\mathrm{D}$ & - & - & + & - & - & - & - & - & - & - & - & - & - & - & - & - \\
\hline SP55 & $\mathrm{D}$ & +++ & - & - & - & - & - & - & - & - & - & - & - & - & - & - & - \\
\hline SP56 & $\mathrm{S}$ & +++ & - & - & + & - & - & - & - & - & - & - & - & +++ & - & - & + \\
\hline \multirow[t]{2}{*}{ AaSS57 } & D & - & - & - & - & - & - & - & + & - & - & - & - & - & - & - & - \\
\hline & $\mathrm{S}$ & - & - & - & - & - & - & - & - & - & - & - & - & - & - & + & - \\
\hline
\end{tabular}

Growth mode: D: dynamic (stirring at $200 \mathrm{rpm}$ ); S: still. Microorganism strains: 1: M. tuberculosis; 2: P. aeruginosa ATCC 27583; 3: E. coli (antibiotic resistant); 4: E. coli ATCC 25922; 5: S. aureus ATCC 25923; 6: S. aureus resistant strain \#8; 7: S. aureus resistant strain \#18; 8: . aureus resistant strain \#115; 9: S. aureus resistant strain \#134; 10: E. faecalis ATCC 29212; 11: S. choleraesuis ATCC 10708; 12: E. cloacae resistant strain \#19; 13: C. albicans ATCC 10231; Tumor cell lines A: MCF-7 (breast); B: HCT-8 (colon); C: B16 (murine melanoma). Antibacterial activity level: + inhibition zone $>10 \mathrm{~mm}$ and $<14 \mathrm{~mm}$; ++ inhibition zone $>15 \mathrm{~mm}$ and $<20 \mathrm{~mm}$; +++ inhibition zone $>20 \mathrm{~mm}$, except for $M$. tuberculosis. Antimycobacterial activity level against $M$. tuberculosis: +++ inhibition at $31.25 \mu \mathrm{g} / \mathrm{mL}$; ++ inhibition at $62.5 \mu \mathrm{g} / \mathrm{mL}$; + inhibition at $125 \mu \mathrm{g} / \mathrm{mL}$. Antiproliferative activity level: + inhibition up to $50 \%$ of cancer cell growth; ++ inhibition between 50 and $75 \%$ of cancer cell growth; +++ inhibition larger than $75 \%$ of cell growth. - Not active. 
Table 3S. Number of crude extracts obtained from marine fungal strains that displayed distinctive chemical profiles and biological activites

\begin{tabular}{|c|c|c|c|c|c|c|}
\hline \multicolumn{2}{|l|}{ Fungi strains } & \multirow{2}{*}{$\frac{\text { PDA-HPLC }}{11}$} & \multirow{2}{*}{$\frac{\text { TLC }}{7}$} & \multirow{2}{*}{$\frac{\text { Antibacterial }}{14}$} & \multirow{2}{*}{$\frac{\text { Antifungal }}{3}$} & \multirow{2}{*}{$\frac{\text { Cytotoxic }}{15}$} \\
\hline Growth mode & still & & & & & \\
\hline & dynamic & 9 & 5 & 18 & 0 & 1 \\
\hline \multirow[t]{4}{*}{ Origin } & sediments & 12 & 8 & 19 & 1 & 9 \\
\hline & algae & 6 & 4 & 12 & 2 & 5 \\
\hline & sponge & 1 & 0 & 0 & 0 & 0 \\
\hline & cnidarian & 1 & 0 & 1 & 0 & 1 \\
\hline
\end{tabular}

Table 4S. Number of crude extracts obtained from marine-derived fungi that presented simultaneously two or three chemical profile and/ or biological activities

\begin{tabular}{|c|c|c|c|c|c|c|c|c|c|c|c|c|c|c|}
\hline $\begin{array}{l}\text { Biological } \\
\text { activities }\end{array}$ & & $\begin{array}{c}(1) \\
+(2)\end{array}$ & $\begin{array}{c}(1) \\
+(3)\end{array}$ & $\begin{array}{r}(1) \\
+(4)\end{array}$ & $\begin{array}{c}(1) \\
+(5)\end{array}$ & $\begin{array}{c}(2) \\
+(3)\end{array}$ & $\begin{array}{c}(2) \\
+(4)\end{array}$ & $\begin{aligned} & (2) \\
+ & (5)\end{aligned}$ & $\begin{array}{c}(3) \\
+(4)\end{array}$ & $\begin{array}{l}(3) \\
+(5)\end{array}$ & $\begin{array}{c}(1) \\
+(2) \\
+(3)\end{array}$ & $\begin{array}{r}(2) \\
+(3) \\
+(4)\end{array}$ & $\begin{array}{c}(2) \\
+(4) \\
+(5)\end{array}$ & $\begin{array}{c}(3) \\
+(4) \\
+(5)\end{array}$ \\
\hline Fungi & still & 1 & 3 & 1 & 3 & 3 & 1 & 3 & 3 & 7 & 0 & 1 & 1 & 1 \\
\hline Growth mode & dynamic & 2 & 3 & 0 & 0 & 1 & 0 & 1 & 0 & 0 & 1 & 0 & 0 & 0 \\
\hline Fungi & sediments & 2 & 4 & 0 & 1 & 4 & 1 & 3 & 1 & 5 & 1 & 1 & 1 & 1 \\
\hline \multirow[t]{3}{*}{ Origin } & algae & 0 & 2 & 1 & 1 & 0 & 0 & 1 & 2 & 2 & 0 & 0 & 0 & 0 \\
\hline & sponge & 0 & 0 & 0 & 0 & 0 & 0 & 0 & 0 & 0 & 0 & 0 & 0 & 0 \\
\hline & cnidarian & 0 & 0 & 0 & 1 & 0 & 0 & 0 & 0 & 0 & 0 & 0 & 0 & 0 \\
\hline
\end{tabular}

Legend: (1): distinctive HPLC-PDA chemical profile (chromatograms with peaks which displayed UV absorptions with $\lambda_{\max }$ above 250 $\mathrm{nm}$ ); (2) Alkaloids present (Dragendorff positive in TLC analysis); (3) Antibacterial positive; (4) Antifungal positive; (5) Cytotoxic positive. 